Final Corrected 5-10-16

How 'social' is recreational running? Findings from a qualitative study in London and implications for public health promotion

Length 6,300 words plus references

Date May 2016 revised July and August 2016

Submitted to Health and Place - Exercise and Environment Special Issue. 


\title{
How 'social' is recreational running? Findings from a qualitative study in London and implications for public health promotion
}

\begin{abstract}
Recreational running is increasingly widespread and could therefore be seen as the obvious target for those hoping to encourage greater public health through exercise. Existing qualitative research on this topic has, however, tended to focus on groups of highly committed runners. It is accordingly unclear whether their findings can be extrapolated to the much larger population of comparatively casual runners. This existing work has also tended to emphasise the social nature of the activity in particular ways. Whilst much recreational running happens alone, most commonly these studies have centred on the establishment of shared identities and group subcultures. Drawing on a study involving accompanied runs and interviews with recreational runners who do not belong to running clubs in London, this paper presents an alternative account. These respondents were relatively uninterested in the idea of proper running technique, ambivalent about the presence of others when running, and reticent about being pulled into a more committed collective practice. In view of how these more casual runners may be of particular interest to public health promoters, this finding suggests future campaigns might do well not to focus too greatly on the potential enjoyments of running community membership and start instead with a different set of social dynamics.
\end{abstract}

\section{Key Points}

- Qualitative research on recreational running can tend to overplay its social character

- Casual runners do not see themselves as part of a collective subculture

- Instead they have an ambivalent and limited engagement with others when running

- Casual runners might therefore be indifferent to certain health promotion messages

\section{Key Words}

Running, exercise, qualitative research, public health, practice, sociality 


\section{Introduction}

This article explores whether and how we can understand recreational running as an explicitly 'social' activity. It is motivated by the potential of recreational running as a public health promotion target (UK Department of Health, 2004; Haskell et al., 2007; Lee 2014; Schnohr 2013). Running is an accessible form of exercise because it requires very little in terms of specialist equipment, expertise and experience (England Athletics, 2013). It is also an activity that can happen in a great range of environments and may therefore be easier to fit into the lives of those who otherwise feel they lack the free time to travel to dedicated exercise environments (MINTEL, 2010; Scheerder et al., 2015a). It is also an activity that is clearly growing in popularity in both the UK (Sport England, 2015) and elsewhere (Scheerder et al. 2015b). Finally and of particular interest to this paper, unlike many sports that require the co-presence of participants, running can happen alone. Our contention is that, if the aim is to encourage its further growth, a solid understanding of how recreational running is undertaken and understood by current practitioners should logically be of help.

Our specific contribution draws on a study of how comparatively casual recreational runners in London, UK make sense of their running. More specifically, we seek to show why we might want to move beyond framings that focus on personal and group identity. Much existing in-depth research work on popular fitness practices more generally, and on running in particular, has concerned itself with how continued participation may rest on enrolling people within a discernible sub-culture of relatively keen practitioners. Yet, for the casual runners described in the present study, running has a largely instrumental orientation. That is to say, it is undertaken for the direct, individual, benefits it produces. For these described in this paper, 'doing running' doesn't require becoming a 'runner'. Yet this is not to say running is asocial, but rather to draw attention to the detail of how exactly 'the social' features in the experience. By exploring these alternative 'socialities', we argue, alternative ideas about how to engage with recreational runners are revealed. These are ideas that are potentially important to how public health practitioners might work to encourage physical fitness activities.

\section{Existing qualitative research and the apparent sociality of running}


Modern life for many residents of high-income countries is largely sedentary. And many studies suggest that it is becoming increasingly so (Hallal et al., 2012; Ng and Popkin, 2012). This is concerning because physical inactivity is recognised to have substantial deleterious impacts on both morbidity and mortality (Knight, 2012; Moore et al., 2012). One positive sign, however, has been the remarkable growth in a range of exercise practices that seek to counter this inactivity. In the UK, though cycling has also seen a significant resurgence over recent years (Sport England, 2015), chief amongst them in terms of popularity would seem to be fitness running, a trend that has also been discerned elsewhere (Spiers et al., 2015; Scheerder et al., 2015a).

In order to understand this phenomenon, one obvious starting point would be with what existing qualitative studies tell us about those who run since these in-depth methods should be better at getting under the skin of runners and revealing what it is for them to run. If we took this approach, we would see that qualitative researchers have examined running in a range of different ways (Smith, 1998; Tulle, 2007; Shipway and Holloway, 2010; Nettleton, 2013; 2015). However, there are also certain discernable commonalities to this work. Of particular interest to us in this regard is how they have explored the apparently 'social' character of running. There are two aspects to this. The first involves the presumption of running being about the enrolment of those who run into a wider group culture or subculture. The argument here is that, as they run, runners come to recognise and learn certain right ways of participating in the activity. The individual exerciser does not just run. Rather through running they become part of an identifiable social group. The second is about how running is accordingly presumed to become a key element of the self-identity of its practitioners. This identity extends beyond immediate benefits such as body tone, weight loss, and overall fitness and comes to include a more intrinsic self-identification as a runner. So, they not only come to be subsumed into a recognisable subculture of running, they also come to see themselves as runners instead of simply people who exercise through running.

This situation is what one might perhaps expect from studies of very committed runners such as those examined by Nettleton $(2013 ; 2015)$. After spending time with middle-aged and elderly fell runners in northern England she shows that through their on-going engagement with the practice of running on fells (mountainous semi-wild rural areas), through individual and organised runs and races, they are involved in the creation and 
reproduction of a distinctive form of 'existential capital'; an experience and bodily knowing that is only available to practitioners within the fell running community. Furthermore, they have a shared respect and camaraderie that, though sometimes unspoken, is born of the pleasures and pains of undertaking fell runs. This is to extend an argument developed by Tulle $(2007 ; 2008)$ in her studies of veteran runners. As with fell runners, Tulle's veterans are highly committed. Faced with the prospect of ending their athletics careers the veteran runners worked together to create a new domain of ageing activity. They created new institutions, new training practices, new events all of which were oriented towards the ageing athletic body. Also drawing on Bourdieu (1984), Tulle argues that, as with fell running, the actions of these veteran runners worked to produce a distinctive field of 'sporting capital', understood as a shared set of performance goals and training techniques; one which subverted existing systems of athletic cultural and somatic capital. To be a veteran runner was to be someone who was part of a wider community of similar runners, and someone who would judge, evaluate, and make sense of themselves in relation to this community. Allen Collinson further emphasises ideas of identification (2005; 2008; Allen Collinson and Hockey, 2007) in her autoethnographic work. A competitive distance runner of two decades standings herself, she traces how this on-going engagement became a core part of her personal identity. This is an identity that is anchored and given sense in its relation not just to her own running, but to the running of others with comparable claims on the activity at her club, at races, during training sesssions and at other events. As with Nettleton's fell runners, and Tulle's veterans, Allen Collinson is not merely someone who runs, she is a runner.

Moving from such committed runners to less fully absorbed runners we might expect to find rather different narratives to emerge. This, however, is not by and large the case. Shipway and colleagues (Shipway and Jones, 2008; Shipway and Holloway, 2010; Shipway et al., 2013) in a series of studies of the 'social worlds' of distance runners also stress that amongst the practitioners they interviewed running has become a central part of their identity. Looking at a broad spectrum of running club participants, they argue that running should be understood as an example of what Stebbins (1992) has called 'serious leisure'. This is to draw on some different conceptual resources to those of Nettleton, Tulle and Allen Collinson. But like them it is to frame the practice of recreational running as an activity that pulls those doing it towards a distinctive running 'career', a career that is defined through relations to others involved in running and marked by 
incrementally increasing levels of commitment that are recognised with reference to others. Shipway and his colleagues recognise that there are different degrees of involvement in the 'social world' of recreational runners, and that many people who run for fitness may stand on the edge of the 'distance running social world' described in their research. However, they are not much interested in exploring these individuals, assuming that in time they will either be pulled into the world of distance running - developing a clear 'career' trajectory - or they drift away from it and simply stop running. Crucially, they also perpetuate the basic assumption that there is indeed a 'social world' in evidence here in the sense that running fundamentally figures as collective. This is an argument that echoes Smith's (1998) study of runners in South Wales. Summarising his key findings, Smith suggests the distance running community can be divided up into three distinct groups; athletes, runners, and joggers with joggers being characterised by their dilettantish and un-committed (and by implication temporary) relationship to running. ${ }^{1}$ However, these go unexamined because he too chooses to focus on those who draw these distinctions from within the running community. We do not know how 'joggers' themselves would think of their actions.

To summarise, much existing qualitative work on recreational running suggests that the activity pulls people into distinctive running subcultures. These subcultures have their own distinct characteristics, and embody distinct ways of practising running and relating to the running body. Through their experience of running and their gradual immersion into its associated subcultures individuals would seem to develop distinct runner identities. This set of conclusions is then further amplified if we also include qualitative work on semi-professional and elite runners (see Bale, 2004; Howe and Morris, 2009). Though it was not always the intent of these researchers to inform health promotion policy, were we to follow the implications of their studies through towards such practical applications, they would seem to imply that public health initiatives should focus on ways of encouraging people to become enmeshed in such exercise subcultures. There are, however, a number of reasons to be skeptical about such an endeavour.

\section{Some concerns with this vision}

This emphasis on the social aspects of recreational running in the studies discussed above is common in qualitative studies of fitness activities more generally such as, to name but a few, Andrews et al. (2005) work on gym goers, Atkinson's triathlete study 
(2008), Throsby's swimmer studies (2013) and Spencer's (2009) work on martial artists. All of these highlight the collective nature and processes of self-identification associated with becoming committed to these fitness practices. However, in the running case particularly, we see three good reasons to be wary of embracing such a vision.

1. First, given that the attractions of recreational running are closely related to its immediate accessibility, its straightforwardness, and the fact that it can so easily be carried out alone, it seems counter intuitive that existing studies have ended up stressing its sociality. In this regard, it is worth noting that three of most popular physical activities right now (running, swimming, cycling) are united in how they can be undertaken alone (unlike the sporting activities that require collective scheduling of teams and competitors) and so may be particularly appealing for those without the time to come together with others. It clearly is the case that the runners studied by Nettleton, Tulle, and Shipman et al. have been enrolled in some kind of running culture. But must all runners be? And how much can we extrapolate from the exceptionally committed runners that dominate these studies?

2. This leads to the second, perhaps more important reason for wariness. Most of the above studies are based on runners who are either members of some form of running club, or those who regularly take part in competitive running events, races and 'fun runs.' For ease of recruitment many of these studies used running clubs to build their sample of respondents. This is an understandable strategy. But it is likely to create a unconscious bias towards over emphasising the importance of particular running socialities. Members of a club are likely to be both more socially oriented in their running, and be more oriented towards learning from others, than non-members. And, returning briefly to the market research mentioned earlier, we know that there are many more people who say they regularly run recreationally than there are people who are either members of running clubs or who take part in any kind of organised fun runs or races (Sport England, 2015; England Athletics, 2013). It also seems many are reticent about being described as 'runners', preferring instead the reduced pressure and expectation associated with saying they merely do 'jogging' (see Keynote, 2013).

3. Finally, it is also worth recognising how certain relatively naturalised modes of doing research may be colouring the picture of recreational running. It is an 
obvious but nonetheless telling point that all the above researchers would probably identify themselves as 'social' scientists. And whilst there are clearly many ways of doing this research, the repertoire of conceptual resources and modes of empirical engagement associated with social science do often end up, perhaps unsurprisingly, emphasising a shared and collective 'social'. In particular, ethnographic work such as that undertaken in many of the already cited studies often ends up discerning a collective 'culture' because the concepts that animate the approach are commonly oriented towards shared phenomena and a strong sense of things being organised collectively. Yet these established tools may be less suited to making sense of more loosely structured activities (Becker, 2007). Moreover, as it often goes with qualitative work, readers are encouraged to reach beyond cases that are positioned as exemplifying and explicating given wider phenenomena - in this case contemporary 'recreational running'. However, if we are to go down this path, we clearly need to be careful that we are extrapolating from the appropriate case (Ragin and Becker, 1992).

There is a small but growing body of literature that focuses on how ordinary fitness practitioners - understood as those who do not necessarily sign up to membership of a subculture - go about their exercise (see for example Crossley 2004; 2006; 2008; Sassatelli, 2010). What this work shows is that there is much variation in how apparently singular fitness practices are undertaken. With this variation in mind, there is a final group of qualitative studies that explore the sociality of running from a different angle and by doing so produce a mixed picture of how runners relate to others. Though Krenichyn (2004; 2006), Gimlin (2010) and Cook et al. (2015) all explore runners' interactions with others in public places such as sidewalks, streets, and parks, they highlight some contrasting elements. Gimlin (2010), Smith (2001) and Cook et al. (2015) point to the conflicts that may arise between runners and non-runners on the street. Yet Krenichyn $(2004 ; 2006)$ highlights feelings of support and inspiration generated through passing encounters with other park goers. This resonates with Stevinson's et al.'s (2015; see also Barnfield 2016; Stevinson and Hickson, 2014) finding that 'Parkrun' participants valued these communal runs partly for their freedom from any on-going obligation to return. Then there are interesting recent attempts to recast the sociality of running by seeing its shared 'social' character as less about recurrent experiences with other people, and more about collectively shared physical infrastructures and temporal arrangements 
(Maller et al. 2016). Taken together these studies suggest some alternative ways of thinking about the sociality of running that go beyond notions of shared culture, group belonging, or self-identification.

We too believe that recreational running needs to be studied in new ways. This is because, as we have started to intimate, the tools and assumptions that have tended to prevail in qualitative work on this topic do not seem to be keeping pace with the actuality of how and why recreational running is happening today. Ideas and actions related to how we conceive of the collective nature of running seem to be changing. Though runners still seem to think of running in some way as a 'social' activity (Petridis, 2015) club running seems less and less central to its popularlity (Scheerder et al., 2015a). One obvious way of responding to these trends, as we now discuss, would be take a different sample.

\section{Studying the 'non-runner runners' of London}

We now turn to our runs and interviews with 20 recreational runners in London. All undertook runs of at least twenty minutes at least three times per week. All were happy to be called recreational, non-competitive, runners. The central difference within the group was that one half of the respondents generally ran outside whilst the other was usually found indoors on gym treadmills. Respondents were recruited informally through our existing social networks and, in line with the current demographic profile of those who run in the UK, most were from the middle classes. They had a range of jobs including university administrators, marketing professionals, lawyers, professional support staff, and IT consultants. Half were women and half were men. Most were either in their 30s or their early 40s. We began with accompanied runs, joining individuals on what they deemed a 'typical' run and talking with them before, after, and as we ran together, about how and why they came to run the way they did. Afterwards we organized recorded interviews in which various aspects of the current running practice that we had observed were examined along with different ideas about running in other ways or environments. All of these interviews were fully transcribed and then coded and analysed using the qualitative analysis software package AtlasTi.

The core objective of the study was to question how it was that these runners became attached to their particular running environments - in effect, how they had come to find 
themselves indoors on the treadmill or outside on streets and in parks (see Hitchings and Latham, 2016). But, in line with the iterative benefits of our in-depth approach, we were also vigilant of what this data had to say to other ways of thinking about running. In this regard, we were mindful from the outset of the importance of the right sampling strategy in that, aware of the predominance of self-confessed 'runners' in existing qualitative studies, our respondents were recruited with some care. More specifically, because we wanted to spend time with comparatively casual runners we introduced our study in a certain way. We were at pains to emphasise to potential recruits that we were interested in talking with those who just 'ran at least three times a week' not those who easily agreed to being defined as 'runners'. Though there were no doubt some respondents who would freely sign up to the idea of being a card-carrying 'runner' we also took the time to reassure others who might otherwise have immediately discounted themselves as eligible. This largely proved successful. Many of our respondents were therefore what we might understand as 'non-runner runners' in the sense that, though they regularly ran, they didn't especially think of themselves in these terms. In what follows we detail how their running might be considered 'social', whilst also highlighting the limitations of trying to link it to membership of an explicit cultural group or sub-culture.

\section{(1) There may be proper ways to run, but we run the way that works for us}

We are running with Oliver. In his early 30s, Oliver works in marketing and runs in a corporate gym near his office in central London. We are on adjacent treadmills. Oliver has started the run at an easy trot. As the treadmill timer hit 5 minutes the speed paddle is flicked up a notch. Then he keeps increasing, first with long gaps, and then with increasing frequency. When we reach $16 \mathrm{k} / \mathrm{hr}$ his running looks frantic, flat out. Holding this speed for a little over a minute he then pitches his torso forward, hands grabbing at the treadmill facia and forearms splayed over the control panel. He's still going fast. But he appears to be leaning on the front of the treadmill in an effort to help himself keep up with the pace he's set on the machine. Then using his thumb he flicks the speed control paddle down a couple of notches. As the distance LED ticks over to $5 \mathrm{~km}$ Oliver presses the emergency stop button and finishes. 
In the follow up interview we asked Oliver how the ordering of his changes of pace worked. Copying Oliver on the treadmill the run felt like it had a very definite structure and purpose. However, Oliver's answer rather confounded this sense: "I tend to warm up, run faster, faster, faster then I slow down and then I stop." Oliver's run was not unusual in its intricacy and idiosyncrasy. Accompanying our runners on their runs - both indoors on treadmills and outside on streets and in parks - we found them varying speeds, engaging in variously intricate warm-ups and warm downs, and using a variety of devices to either monitor their run or distract them from it. But the point was that these various styles of running had developed in a kind of improvised, informal way, without particular reference to wider notions of what was the most effective or enjoyable way to run. Oliver could not recall being taught to run on a treadmill. Running faster and increasing the speed just made the run more interesting. And it also got the job done quicker. This was an account repeated through our observations and interviews.

Our discussions involved a significant diversity of narratives about how and why individual respondents started running. Max's experience was much like that of Oliver. In his early 20 s he had played football, and the declining opportunities to play had led him to start running in his local gym. Matthew had started exercising in early middle age to manage his weight, beginning treadmill running after a shoulder injury had made him unable to use the rowing machines he had preferred. Charlie, a medical sales trainee, had taken up treadmill running as part of a concerted diet and exercise program to lose excess weight. Niamh had started running to lose weight for a wedding and then continued as a result of the unexpected pleasure she derived from it. These different origins affected how respondents ran and their recreational running 'careers' such as they were. Niamh began running by simply 'running around the block.' Persistence lead to greater distances, and the discovery that not only did running help her lose weight, but done with headphones in parks it was enjoyable, and something that made her feel better afterwards. Matthew a treadmill runner, likewise discovered running, while often boring, could also be a tremendous stress relief; after a bad day at work he joked about how he would imagine the running belt was his boss, with his feet repeatedly pounding into him.

Unlike in the accounts of committed runners in Shipway et al., (2013), Tulle (2008) and Nettleton (2013) the way the recreational runners we talked with had come to run how they did was largely happenstance. It certainly did not fit the model of fitness running as 
'serious leisure' which involved the on-going skilled pulling together of knowledge and technique as suggested by Shipway and Jones (2008). Through their own devices they had found ways of exercising that worked, and because they worked they were happy to stick with them. They were largely uninterested in technique. They generally only sought advice when something had gone wrong; running shoes needed replacing, a niggling injury was getting too much, replacement running clothes were felt to be required. But even here they showed only partial deference to expert or insider opinion. Shoes were bought as much because they were a nice colour, or looked fast, as they were for the technical features. Physiotherapists' advice about running gait and style was ignored or only half-heartedly followed. Suggestions of personal trainers for training regimes were listened to and then ignored. Respondents were clear that running was attractive precisely because it was straightforward, 'natural', something they could pretty much work out for themselves. They by and large did not want to get caught up in questions of whether they were doing things correctly or efficiently.

This does not mean that our respondents were uninterested in all forms of evaluation. Rather as Crossley (2006) suggests in his work on gym goers, instead of being focused on external norms this was inwardly directed. These runners were interested in how long, how far, and sometimes how fast, they could run. And they were interested in how such self-evaluations have changed over time. Are they as fit as they were a week ago? Last month? Last year? And unlike the runners in Smith (2000) who whilst being well aware of wider metrics of athletic achievement attempted to avoid comparison out of a shared sense of civility, the recreational runners in our study were largely unaware and uninterested in comparing themselves to such metrics. Evaluation was more about the personal than the social. We saw little interest in connecting their running to broader evaluations of success that are often so important to those with a clear runner identity.

\section{(2) How the presence of others features in the running experience}

Kristin's route takes her through her neighbourhood shopping street and into a local park. An events manager in her early 30s, she normally listens to a podcast; although today she's left her iPod at home. As we circumnavigate the park she makes a point of smiling and saying 'hi' to other park users. As we run, she tells us how she always follows the same 
route. As a result she meets many of the same people each day. She finds this comforting. It is, she goes on, one of the nicest parts of her run.

All the 20 recreational runners we spoke to did most, or indeed all, of their running alone. This was largely by choice. Running with others required coordinating schedules, and that was not necessarily easy - a finding in line with one of the most common wider explanations for the rise of recreational running. But in addition to that, whilst it could be fun to run with others, it could also undermine the ease and benefits respondents valued from their runs. Charlie, the treadmill runner mentioned earlier worried that running with others would stop her running at her own pace. Like many of the runners she also liked listening to music whilst exercising and running with others was taken to preclude that. Niamh found that running with others prevented her from reaching the meditative state that typified her best runs. There was also the problem that sometimes they didn't turn up. This had happened to Joanna, a financial analyst in her early 40s, who whilst she liked the company of running with others - it distracted her from the effort of running - had found when her co-runners cancelled on her at short notice she rarely had the will to undertake the planned run by herself. Yet though there was good reason not to arrange runs with others, clearly they were not running alone. All of our respondents ran in public or semi-public places - either streets and parks, or in gyms. And almost all the runners in some way valued the presence of others. As the vignette of Kristin's run at the start of this section suggests, the presence of others encountered during a run could be of real significance. The configuration of this valuation, however, depended on whether the recreation runner ran indoors or outdoors.

The indoor runners affected a state of what the sociologist Goffman (1963) termed 'civil disattention' since the point of the gym was to get in and exercise. During run-alongs with the indoor runners we noticed the studied ways in which our respondents avoided too much interaction with other exercisers. They watched television, they stared determinedly straight ahead, or obsessively scrutinized their treadmill's control panel. This did not mean treadmill runners were oblivious to others (the whole point of the concept of civil disattention being, of course, that it is something that is co-produced). The gym was understood to be a purposeful space where people came to work out. Socialising was at odds with that ethos. Rather than being an overtly sociable space the space of the gyms used by the respondents operated through what Sassatelli (1999, p, 
236) has termed a meta 'framing' of the activity within it. As long as they had mastered the basic operation of treadmills, the gym environment gave indoor runners the license to get on with exercising in whatever way they wished as everyone else in the environment regardless of overall fitness or competence was engaged in more or less the same overall goal. So though there was no overt interaction or talk between them, the presence of others undertaking comparable activities helped our indoor running respondents to run.

In contrast to the shared singular purpose of the gym, outdoor runners found the fact that their run was taking them out into the everyday bustle of their city attractive. Nearly all complained about the difficulties of crowding, and how this could hinder the rhythm of their run. Yet, outdoor runners found the presence of others, whether other runners or not, engaging. Going for a run offered a very distinctive and valued form of sociality. For Joanna the presence of pedestrians helped distract her from the effort of her run. Others expressed something similar. They told us how running outside connected them to the wider rhythms and happenings of their neighbourhood. This sociality involves very little sustained interaction; anything more than fleeting encounters or exhanges of pleasantries were rare. They were running after all, and in that sense they enjoyed how this carried them away before any more sustained interaction was potentially occasioned. This was a kind of running flaneurie that was as available to the women runners as it was to the men. As in Krenichyn's (2004; 2006; cf. Petridis, 2015) studies of exercisers in a New York park the outdoor runners found value in simply being at ease with others using the space they were.

So, for all our runners running was a largely solitary activity. And, it was often valued precisely for its solitariness - that it allowed people to get away from the demands and immediacy of their day-to-day routines. It was also valued for this because our runners didn't want to have to deal with the potential stress of coordinating with co-participants and there were clear downsides to the experience of running with selected others in any case. In this sense, solitary running allowed them to concentrate on themselves and only themselves, to run at the speeds they wanted, and not to have to engage with others. At the same time, our runners were not completely alone. They exercised in the presence of others. And the way this prescence played into the experience of respondents depended on where and how the individual ran. Nonetheless for both the indoor and outdoor 
runners, having others around when they were running was generally valued - in the gym this provided a social cue that helped them to keep going; in the outdoor spaces this provided a pleasing distraction and the potential for interactions that were enjoyable precisely because of the brevity necessitated by the fact that you were running. So there was an ambivalence and subtlety to whether their running was 'social' - co-ordination with chosen others was unappealing but casual co-presence added to the enjoyment.

\section{(3) Not the start of a running career, more a positive running habit}

We are running with Kelly a marketing manager in her 30s along a central London canal. Dodging the puddles left behind by the morning rain, she maintains a remarkably constant pace. Forty minutes in and we have circled back to where we started. Kelly turns and says "I'm going to start walking in 20 seconds." Having finished that, she declares, "Well, that's my run!"

Kelly started running in her early 20s when the opportunities for more organised forms of exercise dried up - much as in the case of Oliver and Max mentioned earlier. Talking about her running she was keen to stress how little it had changed over the years. Her runs always lasted about 40 minutes. She always runs at the same pace through her run. She always listens to music. And she always runs the same route; the route only changing when she moved apartments, and once she had found a new route she liked she stuck to it. Kelly was not unusual in her adherence to routine. Almost all our respondents stressed the overall lack of variation in their running. Moreover respondents stressed that this was a positive quality. It was something that helped them keep running.

Returning to the accounts of highly committed runners in Tulle (2006), Nettleton (2013; 2015) and Allen Collinson (2005; 2008) we can see a clear sense that they are involved in an ongoing and evolving running 'career'. Such a description does not quite convey our respondents ongoing relationship to their running practice. Rather than a career with its suggestion of a certain coherent narrative arch, our runners made sense of and undertake their running as a productive, valuable, habit that they wish to maintain. This occasionally pulled them out into a deeper commitment to running. Some of the runners we talked to have at various times decided to involve themselves in fun runs, 10k runs, half- and full Marathons. And often these commitments led to at least temporary 
changes in how they ran. They would run longer distances, try and run faster, they would run more often. In a couple of cases they briefly joined running clubs. But the extra effort and change in routines does not seem to pull people ever deeper into a running

culture or a running 'career.' People tended to run a fun run, or a Marathon, and then stop and fall back to their earlier less committed forms of running. And of course there are those like Kelly who have no interest in these kinds of shared events at all. She just wants to keep on running as she is. So, running alone, at least for these runners, is not a failure of cultural or social integration. It was simply the sensible way to proceed.

\section{Conclusion}

This paper began with a review of how ideas about the 'social' character of the activity feature in existing qualitative studies of recreational running. Our contention in doing so was that existing studies have tended to overplay the social aspects of running, or perhaps more accurately have tended to emphasise a certain kind of sociality that may not be so important to many of those who are increasingly taking up the activity. It is certainly true that for some, their continued commitment to recreational running is partly sustained by how they have been pulled into distinctive sub-cultures of practice. Yet, for many less committed runners it seems reasonable to assume that this is not the case. With this contention in mind, we then discussed what our own study of comparatively casual runners - the non-runner runners of London - said about running 'sociality'.

We have learnt that recreational running is for many something that is not built through a strong sense of community or belonging to a well defined subculture of doing. It is social in a range of more implicit senses. Firstly, recreational running is social in as much as it is a mode of physical exercise that is widely recognised as a practical way of exercising and as an activity in which there is no obviously 'right' or 'wrong' way of doing things. This social looseness largely precludes enrolling recreational runners in unwanted and unwelcomed external economies of comparison with others. Secondly, whilst recreational running is an activity that is largely undertaken alone, it is nonetheless still something that takes place in the presence of others. The presence of others, be they fellow exercisers or people involved in other activities, affords a range of socialities that variously helps runners remain on task, provides distractions, and offers a sense of being involved in the communal rhythms of their neighbourhood. As such this sociality is mostly 'light' (Amin and Thrift 2002) in character. And it is valued precisely for its 
lightness. Thirdly, and building on the first and second points, many recreational runners swing between periods when their running is oriented towards fun runs or mass participation running events, and periods when their running is less obviously oriented towards the social. The majority of their running, however, remains focussed towards running alone and in ways that tend to be constant over time. Thus, rather than thinking about recreational runners as having distinctive 'running careers' it is perhaps more useful to understand their running as an enduring positive physical exercise habit; a habit that is only loosely articulated with more formal organising structures of running as an exercise practice (cf. Hitchings and Latham 2016).

But our main point is about how ideas about running (and, by implication, how it is encouraged) circulate within and beyond the relevant social science literature. Since much existing qualitative research on non-elite runners focuses on those who have become enrolled within the various social institutions that surround running there is a danger that recreational running comes to be understood through those institutions. Parallel to this, within health promotion recreational running is often thought of as a sub-branch of the sport of competitive running. As such, recreational running is seen as activity that is naturally the concern of those formal institutions that are also responsible for competitive running (England Athletics, 2013; Scheeder et al., 2015). A follow on effect of this are arguments about existing sporting institutions needing to better support recreational runners, and along with that to find ways to pull such runners into the orbit of more formal, socially oriented, forms of running (see Forsberg 2015; England Athletics, 2013; Wirz, 2015). So, in Denmark we see sports clubs seeking to find ways of engaging unattached runners, while in England Run England the body charged with supporting mass participation in running has emphasised the need to train running group leaders to encourage people to run. For those oriented towards the more obviously social dimensions of exercising such initiatives make sense. However, our argument here is that, whilst we can appreciate how and why such a focus on promoting the social aspects of recreational running has come about, we also need to be careful to recognise that such an approach might not be appropriate for many who wish to run. Certainly they seem questionable in view of the findings of our study.

This is something that public health initiatives might benefit from working with. Whilst opportunities to run together may be important for some, it is equally important to 
consider the ways recreational running works as an individual, largely solitary, activity. This might mean highlighting the light sociality of such exercising, or stressing the benefits of time spent by oneself. It might also involve ensuring that spaces like parks and streets are obviously inviting to recreational runners, as the pre-existing presence of other exercisers may be important to encouraging others. And this, as studies such as Krenichyn (2004; 2006) and Maller et al., (2016) have highlighted, requires paying close attention to the basic physical infrastructure important for recreational running. There is also a need for further studies exploring how the patterns of exercise sociality examined in this paper play out for other popular recreational physical fitness activities. As we have stressed, many exercise practices that are on the rise could well be increasing in popularity precisely because they are not explicitly social in orientation. And this downplaying of the social may involve more than just questions of scheduling and coordination. It may also be intertwined with the personal experiences, internal narratives and plans that gradually develop for those who are not signed up to a subculture. Qualitative approaches can tell us much about how people exercise. But it is important to be attentive to how our assumed ways of working as social scientists may sometimes stand in the way of providing the nuanced evidence needed for developing effective public health interventions.

\section{Acknowledgements}

The research for this paper was funded by the UCL 'Bridging the Gaps' Fund and was undertaken with the support and advice of Courtney Kipps. Our thanks to the reviewers and editors for their helpful advice and encouraging comments. 


\section{References}

Allen Collinson, J., 2005. Emotions, interaction and the injured sporting body. International Review for the Sociology of Sport 40, 2, 221-240.

Allen Collinson, J., 2008. Running the routes together: corunning on knowledge and Action. Journal of Contemporary Ethnography 37, 38-61

Allen Collinson, J. Hockey, J., 2007. 'Working out' identity: distance runners and the management of disrupted identity. Leisure Studies 26, 4, 381-398.

Amin, A. and Thrift, N., 2002. Cities: Reimagining the Urban. Cambridge, Polity.

Andrews, G., Sudwell, M., Sparkes, A., 2005. Towards a geography of fitness: an ethnographic case study of the gym in British bodybuilding culture. Social Science \& Medicine. 60,4, 877-891.

Atkinson, M., 2008. Triathlon, suffering and exciting significance. Leisure Studies 27, 2, 165-180.

Bale, J. 2004. Running Cultures: Racing in Time and Space. London: Routledge.

Barnfield, A., 2016. Public health, physical exercise and non-representational theory - a mixed method study of recreational running in Sofia, Bulgaria. Critical Public Health 26, 3, 281-93.

Becker, H., 2007. Telling About Society. University of Chicago, Chicago.

Bourdieu, P., 1984. Distinction. Routledge, London.

Cook, S., Shaw, J. Simpson, P., 2015. Jography: exploring meanings, experiences and spatialities of recreational road-running, Mobilities. Prepub.

Crossley, N., 2004. The circuit trainer's habitus: reflexive body techniques and the sociality of the workout. Body \& Society 10, 1, 37-69.

Crossley, N., 2006. In the gym: motives, meaning and moral career. Body and Society 12 23-50

Crossley, N., 2008. (Net) Working out: social capital in a private health club. The British Journal of Sociology 59, 3, 475-500.

England Athletics, 2013. A nation that runs: a recreational running and athletics plan for England 2013-2017 Author, Birmingham.

Fixx, J., 1977. The Complete Book of Running. New York, Random House.

Forsberg, P. (2015) Denmark: Running for the sake of running? A profile and segmentation of Danish runners. In: Scheerder, J., Breedveld, K, with Borgers, J. (eds.) Running across Europe: The Rise and Size of One of the Largest Sport Markets. Basingstoke: Palgrave Macmillan. 59-80. 
Gimlin, D., 2010. Uncivil attention and the public runner. Sociology of Sport Journal, 27, $3,264-284$.

Goffman, E., 1963. Behavior in Public Places: Notes On The Social Organization of Gatherings. Free Press, New York.

Hallal, P. C., Martins, R. C., \& Ramírez, A., 2014. The Lancet physical activity observatory: promoting physical activity worldwide. The Lancet 384, 9942, 471-472.

Haskell, W. L., Lee, I-M., Pate, R. R., Powell, K. E., Blair, S. N., Franklin, B. A., ... Bauman, A., 2007. Physical activity and public health: Updated recommendation for adults from the American College of Sports Medicine and the American Heart Association. Circulation 116, 9, 1081-1093.

Hitchings, R. and Latham, L., 2016. Indoor versus outdoor running: understanding how recreational exercise comes to inhabit environments through practitioner talk. Transactions of the Institute of British Geographers. In press.

Howe, P. and Morris, C., 2009. An Exploration of the Co-production of Performance Running Bodies and Natures Within "Running Taskscapes." Journal of Sport and Social Issues, 33, 3, 308-330.

Keynote, 2013. Health Clubs and Leisure Centres Market Report. Author, London.

Knight, J. A., 2012. Physical inactivity: associated diseases and disorders. Annals of Clinical \& Laboratory Science 42, 3, 320-337.

Krenichyn, K., 2004. Women and physical activity in an urban park: Enrichment and support through an ethic of care. Journal of Environmental Psychology, 24, 1, 117-130.

Krenichyn, K., 2006. 'The only place to go and be in the city': women talk about exercise, being outdoors, and the meanings of a large urban park. Health \& Place 12, 4, 631-643.

Latham, A., 2015. The history of a habit: jogging as a palliative to sedentariness in 1960s America. Cultural Geographies 22, 1, 103-126.

Lee, D. C., Pate, R. R., Lavie, C. J., Sui, X., Church, T. S., \& Blair, S. N., 2014. Leisuretime running reduces all-cause and cardiovascular mortality risk. Journal of the American College of Cardiology 64, 5, 472-481.

Maller, C., Nicholls, L, Strengers, Y., 2016. Understanding the Materiality of Neighbourhoods in 'Healthy Practices': Outdoor Exercise Practices in a New Masterplanned Estate Urban Policy and Research 34, 1, 55-72.

MINTEL, 2010. Sport and Exercise: Ten Year Trends. London, Author.

Moore, S., Patel, A., Matthews, C., Berrington de Gonzalez, A., Park, Y., Katki, H., Linet, M., Weiderpass, L., Visvanathan, K., Helzlsouer, K., Thun, M., Gapstur, S., Hartge, P., Lee, I-M., 2012. Leisure time physical activity of moderate to vigorous intensity and mortality: A large pooled cohort analysis. Plos Medicine 9. 11, e1001335. 
Nettleton, S., 2013. Cementing relations within a sporting field: fell running in the English Lake District and the acquisition of existential capital. Cultural Sociology 7, 196210.

Nettleton, S., 2015. Fell runners and walking walls: towards a sociology of living landscapes and aesthetic atmospheres as an alternative to a Lakeland picturesque. The British Journal of Sociology 66, 4, 759-778.

Ng, S., Popkin, B., 2012. Time use and physical activity: a shift away from movement across the globe. Obesity Reviews 13, 659-680.

Petridis, L. 2015. Greece: Mass Running: A New Trend from Ancient Times? In: Scheerder, J., Breedveld, K, with Borgers, J. (eds.) Running across Europe: The Rise and Size of One of the Largest Sport Markets. Basingstoke: Palgrave Macmillan. 140-162.

Ragin, C., Becker, H., 1992. What Is A Case?: Exploring the Foundations of Social Inquiry. Cambridge University Press, Cambridge.

Sassatelli, R., 1999. Interaction order and beyond: a field analysis of body culture within fitness gyms. Body and Society, 5, 2-3, 227-248.

Sassatelli, R., 2010. Fitness Culture: Gyms and the Commercialisation of Discipline and Fun. Palgrave Macmillan, London.

Scheerder, J., Breedveld, K., with Borgers, J. (Eds), 2015a. Running Across Europe: The Rise and Size of One of the Largest Sport Markets. Palgrave Macmillan, London.

Scheerder, J., Breedveld, K., Borgers, J., 2015b. Who is doing a run with the running boom? The growth and governance of one of Europe's most popular s port a ctivities. In: Scheerder, J., Breedveld, K, with Borgers, J. (eds.) Running across Europe: The Rise and Size of One of the Largest Sport Markets. Basingstoke: Palgrave Macmillan. 1-27.

Schnohr, P., Marott, J., Lange, P., Jensen, G., 2013. Longevity in male and female joggers: the Copenhagen City Heart Study. American Journal of Epidemiology 177, 7, 683-689.

Shipway, R., Holloway, I., 2010. Running free: embracing a healthy lifestyle through distance running. Perspectives in Public Health 130, 6, 270-76.

Shipway, R., Jones, I., 2008. 'The great suburban Everest': an 'insiders' perspective on experiences at the 2007 Flora London Marathon. Journal of Sport and Tourism 13, 1, 6177.

Shipway, R., Holloway, I., Jones, I., 2013. Organisations, practices, actors, and events: Exploring inside the distance running social world. International Review for the Sociology of Sport, 48, 3, 259-276.

Smith, G., 2001. Techniques of body neutralization, techniques of body management, 
and the public harassment of joggers. In Cunningham-Burley, S., Backett-Milburn, K., (Eds), Exploring the Body. Palgrave, Basingstoke, pp. 163-82.

Smith, S., 1998. Athletes, runners, and joggers: participant-group dynamics in a sport of 'individuals'. Sociology of Sport Journal 15,1, 174-192.

Smith, S., 2000. British nonelite road running and masculinity: a case of 'running repairs'? Men and Masculinities 3, 2, 187-208.

Spencer, D., 2009. Habit (us), body techniques and body callusing: an ethnography of mixed martial arts. Body \& Society 15, 4, 119-143.

Spiers, A., Harris, S., Charlton, A. and Smale, P., 2015. England: The Governance and History of Running, the Decision to Run and Trends in Running Participation. In: Scheerder, J., Breedveld, K. \& Borgers, J. (eds.) Running across Europe: The Rise and Size of One of the Largest Sport Markets. Basingstoke: Palgrave Macmillan. 81-104.

Sport England, 2015. Active People Survey 2015.

Stebbins, R., 1992. Amateurs, Professionals, and Serious Leisure. McGill-Queen's Press, Montreal.

Stevinson, C., Hickson, M., 2014. Exploring the public health potential of a mass community participation event. Journal of Public Health 36, 268-74.

Stevinson, C., Wiltshire, G., Hickson, M., 2015. Facilitating participation in healthenhancing physical activity: a qualitative study of parkrun. International Journal of Behavioural Medicine, 22, 170-77.

Throsby, K., 2013. 'If I go in like a cranky sea lion, I come out like a smiling dolphin': marathon swimming and the unexpected pleasures of being a body in water. Feminist Review 103, 1, 5-22.

Tulle, E., 2007. Running to run: embodiment, structure and agency amongst veteran elite runners. Sociology 41, 2, 329-346.

Tulle, E. 2008. The aging body and the ontology of aging: athletic competence and later life. Body and Society 14, 3, 1-19.

Wirz, W. (2015) Foreword. In: Scheerder, J., Breedveld, K, with Borgers, J. (eds.) Running across Europe: The Rise and Size of One of the Largest Sport Markets. Basingstoke: Palgrave Macmillan. XX-XI.

UK Department of Health, 2004. Choosing Health? Choosing Activity: A Consultation on How to Increase Physical Activity. Department of Health, London. 
1 . This article is concerned with people who run non-professionally as a recreational activity. For simplicity's sake the article uses the terms 'runners' or 'people who run' to refer to all those who run regularly in this capacity. As is explained as the article develops the practice of running encompasses a broad range of activities; running might be undertaken in wide variety of places, involving significant variations in intensity, variations in duration, and incorporate a diverse range of purposes that may reach beyond a narrow definition of fitness. Some studies (Smith 1998; Cook et al. 2015) have sought to draw a distinction between 'running' and 'jogging', drawing a clear categorical separation between the two. We have not found this a helpful distinction. In this study we use recreational runners to refer to all those run for some form of leisure. The terms jogging and jogger have a long and complicated entomological history which has been explored elsewhere (see Fixx 1978; Latham 2015). 